\title{
Endoscopic ultrasound-guided colo-enterostomy for relief of complete small-bowel obstruction
}

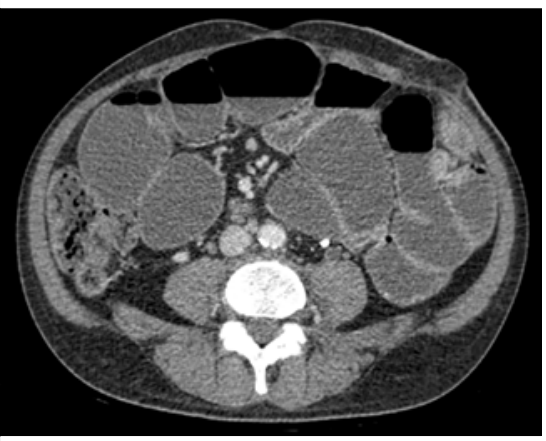

- Fig. 1 Computed tomographic (CT) scan of the abdomen showing dilated loops of small bowel.

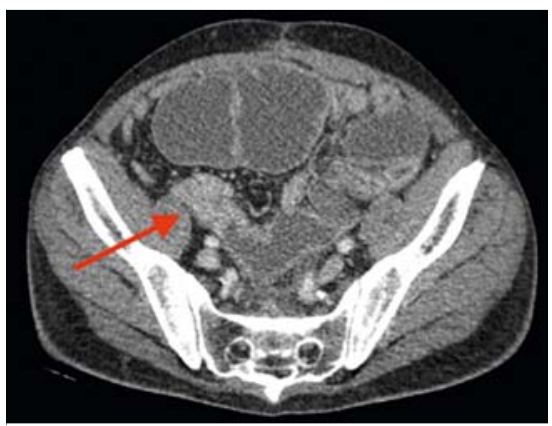

- Fig. 2 Peritoneal implant with complete stenosis at the level of the ileum.

A 40-year-old man with a history of rectal cancer and abdominoperineal amputation was admitted with a complete small bowel obstruction, with no ostomy output for 3 days. Computed tomographic (CT) scan of the abdomen demonstrated massively dilated small-bowel loops ( Fig.1) with a high-grade obstruction at the level of the preterminal ileum due to a peritoneal implant ( $\mathbf{F i g} .2$ ). Pelvic recurrence and bone and liver metastases were also observed. Conservative management for 2 weeks failed to resolve the patient's symptoms. After detailed interdisciplinary discussion with the patient, we decided to attempt endoscopic ultrasound-guided colo-enterostomy using a lumen-apposing metal stent ( $\vee$ Video 1 ).

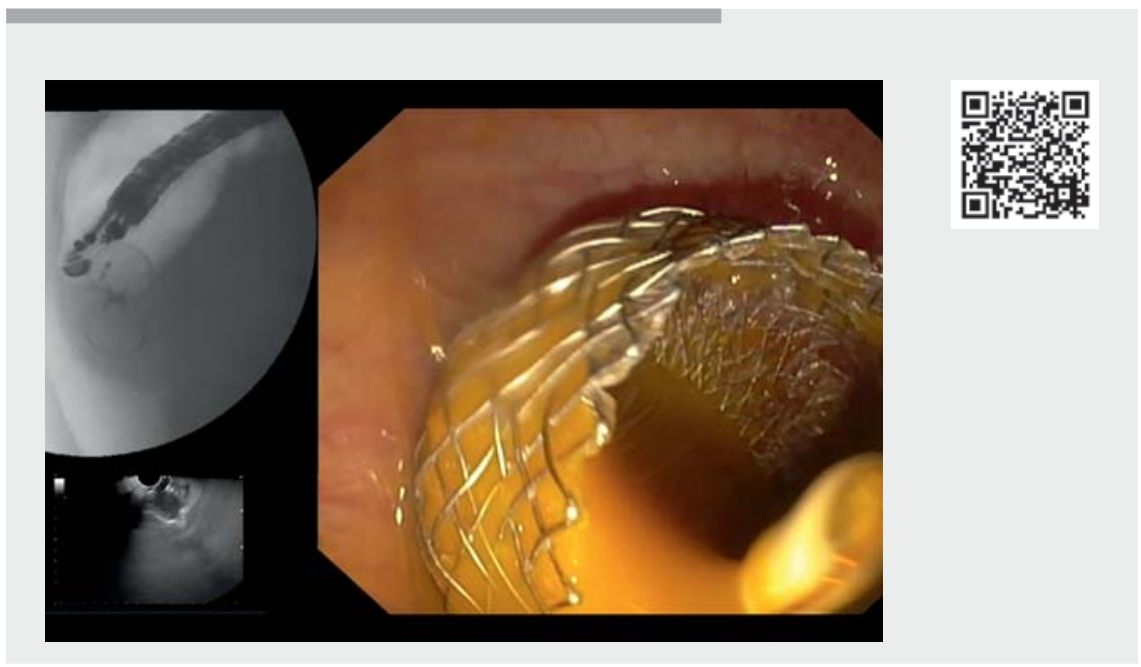

Video 1 Endoscopic ultrasound-guided colo-enterostomy.

A gastroscope was used to advance to the third part of the duodenum. A guidewire was advanced to the jejunum and an 8.5-Fr nasobiliary drain was left in place. Contrast with methylene blue was infused to mark the proximal small bowel under fluoroscopy. Through the ostomy, we advanced a GF-UCT180 curved lineararray echoendoscope (Olympus) over a guidewire to the ascending colon. The most dilated loop of the small bowel with debris-filled fluid and no contrast on fluoroscopy was chosen. A $20-\times 10-\mathrm{mm}$ electrocautery-enhanced lumen-apposing metal stent (Hot Axios; Boston Scientific) was deployed with a freehand technique. Abundant drainage of non-bluestained small-bowel fluid into the colon was observed. Repeat CT scan demonstrated decompression of the small bowel and patency of the colo-enterostomy stent (> Fig. $\mathbf{3}$ ).

The patient improved symptomatically after the procedure and resumed oral feeding within 24 hours of the procedure. Antibiotics were continued for 5 days after the procedure. No immediate postoperative adverse events were noted, and

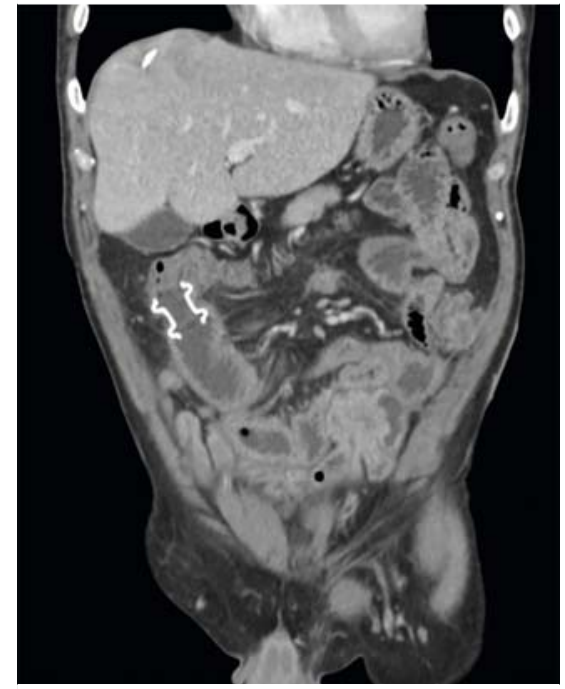

Fig. 3 CT scan of the abdomen with colo-enterostomy between the hepatic flexure and ileum.

the patient was subsequently discharged and followed up as an outpatient.

Only a few cases of EUS-guided colo-enterostomy have been published [1-3]. 
This new technique may be useful in palliative patients in whom surgery is not an appropriate option.

Endoscopy_UCTN_Code_TTT_1AQ_2AF

Competing interests

Dr. Aparicio is a consultant for Boston Scientific.

The authors

Belén Martínez-Moreno, José R. Aparicio Unidad de Endoscopia, Servicio de Medicina Digestiva, ISABIAL Hospital General Universitario de Alicante, Spain
Corresponding author

José R. Aparicio, MD, PhD

Unidad de Endoscopia, Servicio de Medicina

Digestiva, ISABIAL Hospital General

Universitario de Alicante, Avda. Pintor Baeza

s/n , 03013 Alicante, Spain

japariciot@gmail.com

\section{References}

[1] Mai HD, Dubin E, Mavanur AA et al. EUSguided colo-enterostomy as a salvage drainage procedure in a high surgical risk patient with small bowel obstruction due to severe ileocolonic anastomotic stricture: a new application of lumen-apposing metal stent (LAMS). Clin J Gastroenterol 2018; 11 : 282-285

[2] Mir A, Parekh PJ, Shakhatreh M et al. Endoscopic ultrasound-guided creation of an enterocolostomy to relieve malignant bowel obstruction. Endosc Int Open 2019; 7 : 1034-1037

[3] James TW, Nakshabendi R, Baron TH. EUS-guided ileocolonic anastomosis for relief of complete small-bowel obstruction. VideoGIE 2020; 5: 428-430
Bibliography

Endoscopy 2021; 53: 1190-1191

DOI 10.1055/a-1337-2184

ISSN 0013-726X

published online 27.1.2021

(c) 2021. Thieme. All rights reserved.

Georg Thieme Verlag KG, Rüdigerstraße 14,

70469 Stuttgart, Germany

\section{ENDOSCOPY E-VIDEOS}

https://eref.thieme.de/e-videos

Endoscopy E-Videos is a free access online section, reporting 回: on interesting cases and new techniques in gastroenterological endoscopy. All papers include a high quality video and all contributions are freely accessible online.

This section has its own submission website at

https://mc.manuscriptcentral.com/e-videos 